\title{
Phase I dose-escalation study of the HSP90 inhibitor AUY922 in Japanese patients with advanced solid tumors
}

\author{
Toshihiko Doi $\cdot$ Yusuke Onozawa $\cdot$ Nozomu Fuse $\cdot$ Takayuki Yoshino \\ Kentaro Yamazaki · Junichiro Watanabe • Mikhail Akimov • \\ Matthew Robson • Narikazu Boku • Atsushi Ohtsu
}

Received: 2 June 2014 / Accepted: 3 July 2014 / Published online: 25 July 2014

(C) The Author(s) 2014. This article is published with open access at Springerlink.com

\begin{abstract}
Purpose AUY922 is a potent non-geldanamycin inhibitor of heat-shock protein 90 . This study was carried out in Japanese patients to determine the maximum tolerated dose (MTD), and to characterize safety, tolerability and pharmacokinetics of single-agent AUY922.

Methods Japanese patients with advanced solid tumors whose disease had progressed on at least one line of standard therapy, or for whom no standard therapy existed, were treated with AUY922 (intravenous, once-weekly, 28-day cycle, starting dose $8 \mathrm{mg} / \mathrm{m}^{2}$ ).

Results Thirty-one patients were treated. Two DLTs were reported in one patient of the $54 \mathrm{mg} / \mathrm{m}^{2}$ cohort; fatigue and decreased appetite (both Grade 3, resolving to Grade 1 within 8 days). No MTD was determined, and the dose recommended for Phase II studies was determined to be $70 \mathrm{mg} / \mathrm{m}^{2}$ once-weekly. Most common drug-related toxicities were diarrhea, night blindness and nausea. Grade 1 and 2 visual toxicities at high AUY922 doses $\geq 22 \mathrm{mg} / \mathrm{m}^{2}$ were observed. Ten patients (32\%) achieved a best overall
\end{abstract}

T. Doi $(\varangle) \cdot$ N. Fuse $\cdot$ T. Yoshino $\cdot$ A. Ohtsu

National Cancer Center Hospital East, 6-5-1 Kashiwanoha,

Kashiwa, Chiba 277-8577, Japan

e-mail: tdoi@east.ncc.go.jp

Y. Onozawa $\cdot$ K. Yamazaki $\cdot$ J. Watanabe $\cdot$ N. Boku

Shizuoka Cancer Center, 1007 Shimonagakubo, Nagaizumi-cho,

Sunto-gun, Shizuoka 411-8777, Japan

\section{Akimov}

Novartis Pharma AG, 4002, Novartis Campus, Basel, Switzerland

\section{Robson}

Novartis Pharma K.K., 4-12-24, Nishi-azabu, Minato-ku,

Tokyo 106-0031, Japan response of stable disease, and one patient ( $3 \%$ ) achieved a confirmed partial response.

Conclusion Overall, AUY922 exhibited acceptable toxicities and demonstrated potential clinical activity in Japanese patients, with similar safety and pharmacokinetic profiles to those reported in a preceding global Phase I study in Western patients (CAUY922A2101).

Keywords AUY922 - Clinical trial · HSP90 - Japanese · Phase I

\section{Introduction}

Heat-shock proteins (HSPs) are molecular chaperones that assist in the structural formation, folding and activation of a wide variety of oncogenic client proteins involved in diverse cellular processes such as apoptosis, proliferation, signal transduction and transcription control [1-4]. These client proteins include human epidermal growth factor receptor 2 (HER2), estrogen receptor, epidermal growth factor receptor, platelet-derived growth factor receptor, vascular endothelial growth factor, AKT, c-KIT and c-MET $[1,2]$. HSP90 is the most abundant molecular chaperone and is essential for cell survival, proliferation and apoptosis. These processes are significantly affected by HSP90 inhibition, and therefore, HSP90 inhibitors are considered to have a strong therapeutic potential in a wide variety of tumor types [5]. Indeed, HSP90 inhibitors degrade a variety of oncogenic client proteins [6-8]. In addition, HSP90 inhibitors show synergy with various chemotherapeutic agents in murine tumor models and sensitize tumor cells to their cytotoxic effects [6-8].

AUY922 (5-[2,4-dihydroxy-5-isopropyl-phenyl]- $N$-ethyl4-[4-(morpholinomethyl) phenyl]isoxazole-3-carboxamide) 
is a highly potent, isoxazole-based, non-geldanamycin HSP90 inhibitor that inhibits the ATPase activity of HSP90, and leads to misfolding of client proteins [9, 10]. AUY922 has significant antitumor activity in a wide range of cancer cell lines and inhibits tumor growth in murine xenograft models [9-13]. In a preceding global Phase I study in Western patients (CAUY922A2101), the recommended Phase II dose (RP2D) of AUY922 was determined to be $70 \mathrm{mg} /$ $\mathrm{m}^{2}$ intravenous (IV) once-weekly [14]. Phase II studies have been initiated in patients with HER2-positive breast cancer, gastric cancer and non-small cell lung cancer to further investigate the safety profile and clinical efficacy of AUY922 as a single agent and in combination with other agents. In these global Phase II studies, AUY922 was well tolerated with promising clinical activity as single-agent therapy, as well as in combination with other agents, in some sub-populations with actively progressing disease $[15,16]$.

In the present open-label, Phase I dose-escalation study, the safety, pharmacokinetics (PK) and clinical efficacy of AUY922 were evaluated in Japanese patients with advanced solid tumors. The primary objective was to determine the maximum tolerated dose (MTD) of AUY922 as a single agent when administered intravenously on a onceweekly schedule. Secondary objectives were to characterize the safety and tolerability of AUY922 treatment, evaluate the preliminary antitumor activity of AUY922 as a single agent and observe the PK profile of AUY922 and its metabolite.

\section{Materials and methods}

\section{Patient population}

Adult patients (aged $\geq 20$ years) with histologically confirmed, advanced solid tumors whose disease had progressed on at least one line of standard systemic therapy, or for whom no standard therapy existed, were eligible. Inclusion criteria included Eastern Cooperative Oncology Group performance status $\leq 2$ and life expectancy $\geq 12$ weeks. Laboratory parameters required were absolute neutrophil count $\geq 1.5 \times 10^{9} / \mathrm{l}$, hemoglobin $\geq 8.5 \mathrm{~g} / \mathrm{dl}$, platelets $\geq 100 \times 10^{9} / 1$, potassium, calcium, magnesium, phosphorus within normal limits or correctable with supplements, aspartate aminotransferase and alanine aminotransferase $\leq 2.5 \times$ upper limit of normal (ULN), serum bilirubin $\leq 1.5 \times$ ULN, serum albumin $>2.5 \mathrm{~g} / \mathrm{dl}$, and serum creatinine $\leq 1.5 \times$ ULN or 24 -hour clearance $\geq 50 \mathrm{ml} / \mathrm{min}$.

Exclusion criteria included central nervous system metastases, acute or chronic liver or renal disease and previous treatment with histone deacetylase or HSP90 inhibitors. Patients were excluded who had clinically significant heart disease, QTc $\geq 450 \mathrm{~ms}$ on screening electrocardiogram (ECG), ischemic heart disease, heart failure, ECG abnormalities, atrial fibrillation, atrial flutter or ventricular arrhythmias including ventricular tachycardia or Torsades de Pointes, or a history (or family history) of long QT syndrome. Patients receiving any medication that had a risk of prolonging the QTcF interval or inducing Torsades de Pointes, and those with disorders known to be caused by a deficiency in bilirubin glucuronidation (e.g., Gilbert's syndrome), were also excluded.

This trial was conducted in accordance with the Declaration of Helsinki and the Good Clinical Practice guidelines (Japanese Ministry of Health, Labour and Welfare). All studies were performed after approval by local ethical committee/institutional review board. Written informed consent was obtained from all patients before screening.

\section{Dosing and administration}

AUY922 was administered by IV infusion over $1 \mathrm{~h}$, once every week (Days 1, 8, 15 and 22) until disease progression, unacceptable toxicity, or withdrawal by investigator decision or patient refusal. The starting dose was $8 \mathrm{mg} /$ $\mathrm{m}^{2}$, and treatment cycles were 28 days. Intra-patient dose escalation was not permitted. An adaptive Bayesian logistic regression model (BLRM), guided by the escalation with overdose control (EWOC) principle, was used to guide dose escalations [17]. The EWOC principle mandates the potential doses recommended for the next cohort and the estimated MTD have less than $25 \%$ posterior probability of DLT in the excessive toxicity interval $(33,100 \%)$. The information about dose-limiting toxicity (DLT) available from the CAUY922A2101 study at the time of the start of this study supported a starting dose of $8 \mathrm{mg} / \mathrm{m}^{2}[50 \%$ of the highest dose $\left(16 \mathrm{mg} / \mathrm{m}^{2}\right)$ associated with no DLTs]. Toxicities at both the 8 and $16 \mathrm{mg} / \mathrm{m}^{2}$ dose levels in that study had been mild, and the preliminary PK results had shown no accumulation of the drug up to a dose of $16 \mathrm{mg} /$ $\mathrm{m}^{2}$. The occurrence of DLTs was evaluated during Cycle 1. A minimum of three patients were enrolled in a cohort, and the estimated MTD was continuously updated using the BLRM, and a minimum of six patients were planned to be enrolled at the MTD level. The final recommended dose was based on overall safety assessments and MTD estimated by the BLRM, which was the dose of AUY922 with the highest posterior probability of DLT in the target interval $(16,33 \%)$ among the doses fulfilling the EWOC principle [18]. A minimum of 15 patients were required for the BLRM model to determine the MTD. AUY922 was supplied as $10-\mathrm{ml}$ ampoules of a $5-\mathrm{mg} / \mathrm{ml}$ solution, which was diluted into $5 \%$ dextrose or glucose to a maximum infusion volume of $500 \mathrm{ml}$, under aseptic conditions and protected from light to prevent the photolabile drug from 
Table 1 Patient demographics, and baseline disease characteristics

\begin{tabular}{|c|c|c|c|c|c|c|c|c|}
\hline \multirow[t]{2}{*}{ Characteristic } & \multicolumn{8}{|c|}{ AUY922 dose $\left(\mathrm{mg} / \mathrm{m}^{2}\right)$} \\
\hline & $8(n=3)$ & $16(n=3)$ & $22(n=3)$ & $28(n=5)$ & $40(n=3)$ & $54(n=6)$ & $70(n=8)$ & Total, $n(\%)(N=31)$ \\
\hline Mean age, years & 51.3 & 61.7 & 52.7 & 53.6 & 62.0 & 62.3 & 59.4 & 58.1 \\
\hline \multicolumn{9}{|l|}{ Gender, $n$} \\
\hline Male & 2 & 1 & 3 & 2 & 1 & 2 & 4 & $15(48)$ \\
\hline \multicolumn{9}{|l|}{ ECOG PS, $n$} \\
\hline 0 & 2 & 3 & 2 & 3 & 3 & 4 & 4 & $21(68)$ \\
\hline 1 & 1 & 0 & 1 & 2 & 0 & 2 & 4 & $10(32)$ \\
\hline \multicolumn{9}{|l|}{ Stage (current), $n$} \\
\hline IV & 3 & 3 & 3 & 3 & 3 & 6 & 8 & $29(94)$ \\
\hline IVa & 0 & 0 & 0 & 1 & 0 & 0 & 0 & $1(3)$ \\
\hline $\mathrm{IVb}$ & 0 & 0 & 0 & 1 & 0 & 0 & 0 & $1(3)$ \\
\hline \multicolumn{9}{|l|}{ Tumor type, $n$} \\
\hline Rectum & 0 & 10 & 2 & 0 & 0 & 2 & 5 & $10(32)$ \\
\hline Colon & 1 & 1 & 1 & 0 & 1 & 2 & 1 & $7(23)$ \\
\hline Breast & 0 & 0 & 0 & 2 & 1 & 1 & 1 & $5(16)$ \\
\hline Head and neck & 1 & 0 & 0 & 0 & 1 & 0 & 0 & $2(7)$ \\
\hline Pancreas & 0 & 0 & 0 & 1 & 0 & 0 & 1 & $2(7)$ \\
\hline Stomach & 1 & 1 & 0 & 0 & 0 & 0 & 0 & $2(7)$ \\
\hline Eesophagus & 0 & 0 & 0 & 1 & 0 & 0 & 0 & $1(3)$ \\
\hline Gall bladder ducts & 0 & 0 & 0 & 1 & 0 & 0 & 0 & $1(3)$ \\
\hline Other & 0 & 0 & 0 & 0 & 0 & 1 & 0 & $1(3)$ \\
\hline
\end{tabular}

ECOG PS Eastern Cooperative Oncology Group performance status

decomposition. Doses were individually adjusted according to body surface area measured at baseline.

\section{Safety assessments}

Toxicity was graded according to the National Cancer Institute Common Toxicity Criteria version 3.0. DLTs were defined as clinically relevant adverse events (AEs; mainly Grade 3 or 4) or abnormal laboratory values, occurring within 28 days following the first dose of AUY922 in Cycle 1. Tumor response was assessed by computed tomography or magnetic resonance imaging, and using Response Evaluation Criteria in Solid Tumors version 1.0 for efficacy evaluations.

Based on reports of Grade 1-3 visual symptoms after weekly administration of AUY922 at dose levels of $\geq 40 \mathrm{mg} / \mathrm{m}^{2}$ in the CAUY922A2101 study, standard ophthalmological assessments were implemented at baseline, at the time of reported visual symptom(s) (if any) and at the end of treatment.

Pharmacokinetic analysis

Validated liquid chromatography-tandem mass spectrometry assay was used for PK assessments of AUY922 and its glucuronide metabolite BJP762. PK assessments were carried out on blood samples obtained pre-infusion and at 5, 15 , and $30 \mathrm{~min}$ and $1 \mathrm{~h}$ during infusion, followed by 5 and 30 min and 1, 2, 4, 5, 8, 24, 48 and 72-h post-infusion on Cycle 1 Day 1 and Cycle 2 Day 1. A non-compartmental analytical method was used to calculate PK parameters of maximum observed concentration $\left(C_{\max }\right)$, time at which $C_{\max }$ occurred $\left(T_{\max }\right)$, terminal half-life $\left(\mathrm{T}_{1 / 2}\right)$, and area under the curve (AUC), for AUY922 and BJP762 in blood, utilizing WinNonlin Pro version 5.2.

\section{Results}

Patient characteristics and treatment

A total of 31 patients were treated in seven dose cohorts $(8$, $16,22,28,40,54$ and $70 \mathrm{mg} / \mathrm{m}^{2}$ ) between November 2008 and July 2011 (Table 1). Median duration of drug exposure was 7.3 weeks (range $0.1-58.1$ weeks) and $55 \%$ of patients underwent 1 or 2 treatment cycles [7 patients $(23 \%)$ and 10 patients (32\%), respectively]. The median relative dose intensity was 1.0 (range $0.7-1.0$ ). At the time of data cutoff (5 July 2011), two patients were still receiving treatment on the study. The remaining 29 patients discontinued 
Table 2 Most common adverse events ( $\geq 10 \%$ and Grade $3 / 4$ ) potentially related to AUY922 treatment

\begin{tabular}{|c|c|c|c|c|c|c|c|c|c|}
\hline \multirow[t]{2}{*}{ Adverse event, $n^{\mathrm{a}}$} & \multirow[t]{2}{*}{ Grade } & \multicolumn{8}{|c|}{ AUY922 dose $\left(\mathrm{mg} / \mathrm{m}^{2}\right)$} \\
\hline & & $8(n=3)$ & $16(n=3)$ & $22(n=3)$ & $28(n=5)$ & $40(n=3)$ & $54(n=6)$ & $70(n=8)$ & Total, $n(\%)(N=31)$ \\
\hline \multirow[t]{2}{*}{ Diarrhea } & All & 0 & 0 & 2 & 4 & 2 & 5 & 7 & $20(65)$ \\
\hline & $3 / 4$ & 0 & 0 & 0 & 0 & 0 & 1 & 0 & $1(3)$ \\
\hline \multirow[t]{2}{*}{ Night blindness } & All & 0 & 0 & 2 & 2 & 1 & 5 & 3 & $13(42)$ \\
\hline & $3 / 4$ & 0 & 0 & 0 & 0 & 0 & 0 & 0 & 0 \\
\hline \multirow[t]{2}{*}{ Nausea } & All & 0 & 0 & 0 & 0 & 2 & 2 & 3 & $7(23)$ \\
\hline & $3 / 4$ & 0 & 0 & 0 & 0 & 0 & 0 & 0 & 0 \\
\hline \multirow[t]{2}{*}{ Decreased appetite } & All & 0 & 1 & 1 & 0 & 0 & 1 & 3 & $6(19)$ \\
\hline & $3 / 4$ & 0 & 0 & 0 & 0 & 0 & 1 & 0 & $1(3)$ \\
\hline \multirow[t]{2}{*}{ Fatigue } & All & 0 & 0 & 0 & 2 & 0 & 3 & 1 & $6(19)$ \\
\hline & $3 / 4$ & 0 & 0 & 0 & 0 & 0 & 1 & 0 & $1(3)$ \\
\hline \multirow[t]{2}{*}{ Rash } & All & 0 & 2 & 0 & 1 & 0 & 2 & 1 & $6(19)$ \\
\hline & $3 / 4$ & 0 & 0 & 0 & 0 & 0 & 0 & 0 & 0 \\
\hline \multirow[t]{2}{*}{ Vomiting } & All & 0 & 0 & 0 & 0 & 1 & 1 & 3 & $5(16)$ \\
\hline & $3 / 4$ & 0 & 0 & 0 & 0 & 0 & 0 & 0 & 0 \\
\hline \multirow[t]{2}{*}{ Headache } & All & 0 & 0 & 0 & 0 & 0 & 0 & 3 & $3(10)$ \\
\hline & $3 / 4$ & 0 & 0 & 0 & 0 & 0 & 0 & 0 & 0 \\
\hline \multirow[t]{2}{*}{ Lymphopenia } & All & 0 & 0 & 0 & 2 & 0 & 1 & 0 & $3(10)$ \\
\hline & $3 / 4$ & 0 & 0 & 0 & 0 & 0 & 0 & 0 & 0 \\
\hline \multirow[t]{2}{*}{ Photopsia } & All & 0 & 0 & 1 & 1 & 0 & 0 & 1 & $3(10)$ \\
\hline & $3 / 4$ & 0 & 0 & 0 & 0 & 0 & 0 & 0 & 0 \\
\hline \multirow[t]{2}{*}{ Pruritis } & All & 0 & 1 & 0 & 0 & 0 & 1 & 1 & $3(10)$ \\
\hline & $3 / 4$ & 0 & 0 & 0 & 0 & 0 & 0 & 0 & 0 \\
\hline
\end{tabular}

Patients who experienced more than one occurrence of the same event are only counted once within each category

${ }^{a}$ By preferred term

the study treatment, mainly due to disease progression (27 patients), and two patients discontinued as a result of AEs related to study drug (one patient each in the 54 and $70-\mathrm{mg} /$ $\mathrm{m}^{2}$ cohorts).

\section{Safety and tolerability}

The most common AEs, regardless of relationship to study drug, were diarrhea (65\%), night blindness $(42 \%)$, nausea and fatigue (both $29 \%$ ). Mild-to-moderate diarrhea (65\%), night blindness $(42 \%)$ and nausea $(23 \%)$ were the most commonly reported AEs possibly related to AUY922 treatment across all doses (Table 2). Visual toxicities, including night blindness, photopsia, cataract, eye disorder, optic neuritis and blurred vision were observed at dose levels of $22-70 \mathrm{mg} / \mathrm{m}^{2}$; all were Grade 1 or 2 . No patients discontinued AUY922 treatment due to the visual toxicities, which were reversible upon discontinuation of treatment. None of the visual AEs were reported as DLTs. Fifteen patients (48 \%) experienced AEs requiring dose modification or interruption. Of these, night blindness (six patients) and eye disorder (two patients) were reported. Eight patients (26\%) experienced serious AEs (SAEs) and SAEs considered to be related to the study drug were reported in two patients. One patient died during the study as a result of disease progression, which was considered to be unrelated to study drug.

The dose-determining set (DDS) consisted of (1) all patients who received at least three doses of AUY922 within the first cycle, were observed for $\geq 28$ days following the first dose, and completed all safety evaluations in Cycle 1, or (2) any patient who had a DLT within Cycle 1 . The DDS was used for the BLRM analyses in the determination of MTD. Among these patients $(n=28)$, one patient $(3.6 \%)$ in the $54-\mathrm{mg} / \mathrm{m}^{2}$ cohort experienced DLTs; two AEs (Grade 3 fatigue and Grade 3 decreased appetite) were considered to be DLTs and both resolved to Grade 1 within 8 days. Two patients who received the $70 \mathrm{mg} / \mathrm{m}^{2}$ dose required repeated dose interruption due to visual adverse events, and both patients ultimately received a dose reduction to $54 \mathrm{mg} / \mathrm{m}^{2}$. Although the BLRM would have permitted dose escalation beyond $70 \mathrm{mg} / \mathrm{m}^{2}$, a decision to stop further dose escalation was taken based on an assessment by investigators of the potential risk of visual toxicities. Visual toxicities at the higher doses ( $22 \mathrm{mg} / \mathrm{m}^{2}$ and above) among those tested 
Table 3 Summary of PK parameters (mean $\pm \mathrm{SD}$, unless otherwise stated) at Cycle 1 Day 1 for blood AUY922 [28$70 \mathrm{mg} / \mathrm{m}^{2}$ (four highest doses)]

$P K$ pharmacokinetics, $S D$ standard deviation

${ }^{a}$ Data missing for one patient

Fig. 1 Mean AUY922 concentration-time profiles in blood on Cycle 1 Day 1

\begin{tabular}{lllll}
\hline AUY922 PK parameter & \multicolumn{4}{l}{ AUY922 dose $\left(\mathrm{mg} / \mathrm{m}^{2}\right)$} \\
\cline { 2 - 5 } & $28(n=5)$ & $40(n=3)$ & $54(n=6)$ & $70(n=8)$ \\
\hline$T_{\max }[$ median, h (range) $]$ & $0.50(0.48-1.07)$ & $1.05(0.50-1.05)$ & $0.76(0.48-1.17)$ & $1.02(0.23-1.17)$ \\
$C_{\max }(\mathrm{ng} / \mathrm{ml})$ & $457 \pm 101$ & $710 \pm 42$ & $1,050 \pm 118$ & $1,100 \pm 118$ \\
$\mathrm{AUC}_{(0-\text { last })}(\mathrm{h} \cdot \mathrm{ng} / \mathrm{ml})$ & $6,810 \pm 1,090$ & $6,960 \pm 1,270$ & $8,880 \pm 1,710$ & $8,540 \pm 895$ \\
$\mathrm{AUC}_{(0-\text {-inf })}(\mathrm{h} \cdot \mathrm{ng} / \mathrm{ml})$ & $9,550 \pm 2,460$ & $11,400 \pm 3470^{\mathrm{a}}$ & $12,300 \pm 2720^{\mathrm{a}}$ & $12,600 \pm 1,720$ \\
$\mathrm{CL}(\mathrm{l} / \mathrm{h})$ & $4.79 \pm 1.68$ & $5.74 \pm 1.16^{\mathrm{a}}$ & $7.24 \pm 1.97^{\mathrm{a}}$ & $8.60 \pm 1.30$ \\
$\mathrm{~V}_{\mathrm{z}}(\mathrm{l})$ & $646 \pm 111$ & $980 \pm 132^{\mathrm{a}}$ & $1,190 \pm 151^{\mathrm{a}}$ & $1,570 \pm 293$ \\
$\mathrm{~T}_{1 / 2}(\mathrm{~h})$ & $98.7 \pm 23.0$ & $123.0 \pm 40.8^{\mathrm{a}}$ & $120.0 \pm 28.5^{\mathrm{a}}$ & $127.0 \pm 18.8$ \\
\hline
\end{tabular}

Semi-logarithmic view

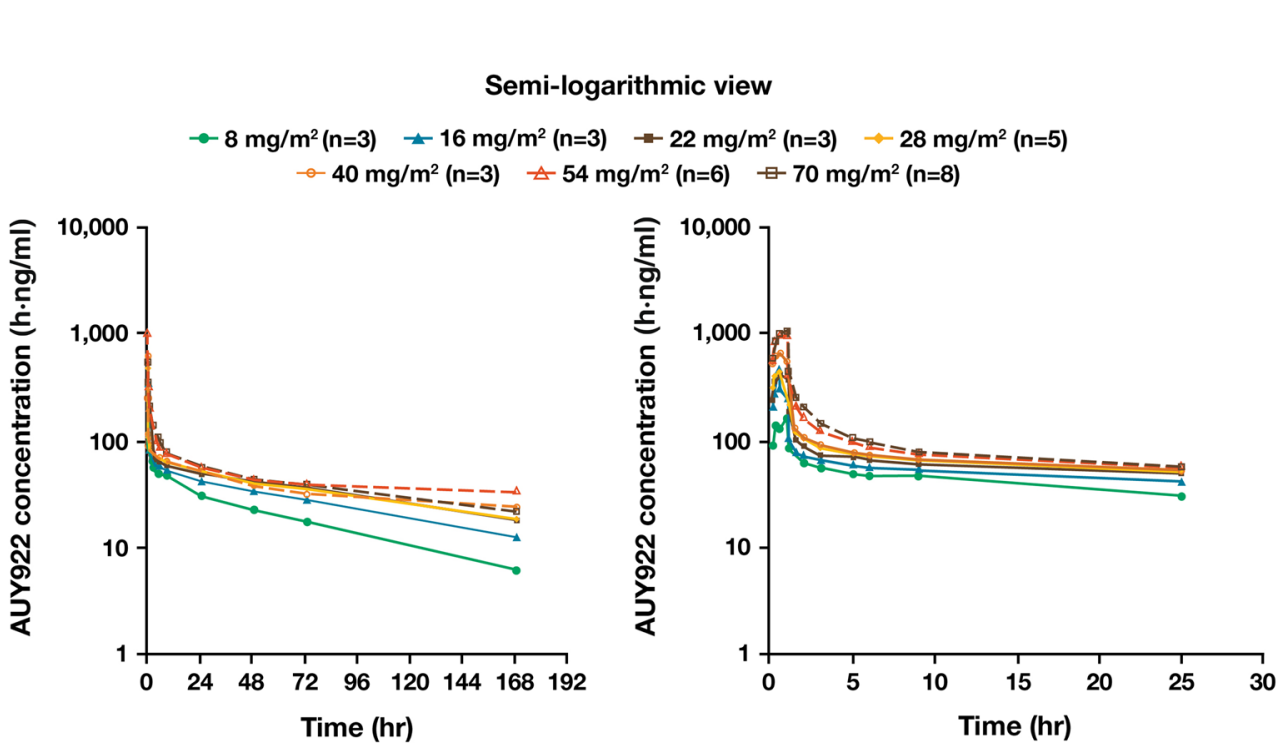

633
Fig. 2 Relationship between AUY922 dose and blood pharmacokinetics parameters

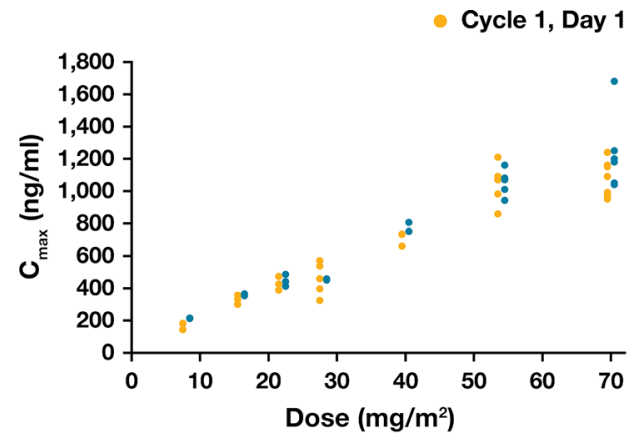

were observed, most commonly night blindness and photopsia, although these were only Grade 1 or 2 . As a result, the MTD was not determined, and the RP2D was, therefore, declared as $70 \mathrm{mg} / \mathrm{m}^{2}$ once-weekly IV over $1 \mathrm{~h}$.

\section{Pharmacokinetics}

AUY922 reached peak concentrations in blood around the end of the infusion. Following the initial rapid decline in concentration levels after the IV administration was completed, blood AUY922 concentration declined slowly, with a mean $\mathrm{T}_{1 / 2}$ of $127 \mathrm{~h}$ at $70 \mathrm{mg} / \mathrm{m}^{2}$ (Table 3; Fig. 1). The $\mathrm{T}_{1 / 2}$ was prolonged with increasing dose $\left(64 \mathrm{~h}\right.$ at $8 \mathrm{mg} / \mathrm{m}^{2}$ to $127 \mathrm{~h}$ at $70 \mathrm{mg} / \mathrm{m}^{2}$ ). $C_{\max }$ for both AUY922 and the metabolite BJP762 generally increased in a dose-proportional manner over the entire dose range. $\mathrm{AUC}_{\text {last }}$ of AUY922 increased with dose (from 8 to $28 \mathrm{mg} / \mathrm{m}^{2}$ ), but was saturated at higher dose levels (Fig. 2; Tables 3, 4). Due to limited sampling time points, the plasma concentration-time profile could not be fully characterized; $C_{\max }$ and AUC for AUY922 in plasma had a tendency to increase in a dose-proportional manner even at the higher dose levels $\left(40-70 \mathrm{mg} / \mathrm{m}^{2}\right)$. 
Table 4 Summary of PK parameters (mean \pm SD, unless otherwise stated) at Cycle 1 Day 1 for blood BJP762 [28-70 mg/m² (four highest doses of AUY922)]

\begin{tabular}{lllll}
\hline BJP762 PK parameter & AUY922 dose $\left(\mathrm{mg} / \mathrm{m}^{2}\right)$ & & & \\
\cline { 2 - 5 } & $28(n=5)$ & $40(n=3)$ & $54(n=6)$ & $70(n=8)$ \\
\hline$T_{\max }[$ median, h (range)] & $1.07(1.05-1.17)$ & $1.05(1.05-1.07)$ & $1.08(1.02-1.22)$ & $1.13(1.00-1.23)$ \\
$C_{\max }(\mathrm{ng} / \mathrm{ml})$ & $611 \pm 201$ & $964 \pm 775$ & $1,060 \pm 569$ & $1,330 \pm 904$ \\
$\mathrm{AUC}_{(0-\text { last })}(\mathrm{h} \cdot \mathrm{ng} / \mathrm{ml})$ & $3,700 \pm 2,170$ & $5,690 \pm 5,250$ & $6,320 \pm 4,650$ & $5,530 \pm 3,320$ \\
$\mathrm{AUC}_{(0-\text {-inf })}(\mathrm{h} \cdot \mathrm{ng} / \mathrm{ml})$ & $3,940 \pm 2,320$ & $5,830 \pm 5,300$ & $6,770 \pm 5200^{\mathrm{a}}$ & $5,020 \pm 3340^{\mathrm{b}}$ \\
$\mathrm{T}_{1 / 2}(\mathrm{~h})$ & $59.1 \pm 28.8$ & $33.1 \pm 12.1$ & $49.1 \pm 24.0^{\mathrm{a}}$ & $46.5 \pm 27.9^{\mathrm{b}}$ \\
\hline
\end{tabular}

$P K$ pharmacokinetics, $S D$ standard deviation

${ }^{a}$ Data missing for one patient

b Data missing for two patients

Table 5 Best overall response (Response Evaluation Criteria in Solid Tumors)

\begin{tabular}{|c|c|c|c|c|c|c|c|c|}
\hline \multirow[t]{2}{*}{ Response, $n$} & \multicolumn{8}{|c|}{ AUY922 dose $\left(\mathrm{mg} / \mathrm{m}^{2}\right)$} \\
\hline & $8(n=3)$ & $16(n=3)$ & $22(n=3)$ & $28(n=5)$ & $40(n=3)$ & $54(n=6)$ & $70(n=8)$ & Total, $n(\%)(N=31)$ \\
\hline Complete response & 0 & 0 & 0 & 0 & 0 & 0 & 0 & 0 \\
\hline Partial response & 0 & 0 & 0 & 0 & 0 & 1 & 0 & $1(3)$ \\
\hline Stable disease & 1 & 1 & 0 & 1 & 1 & 1 & 5 & $10(32)$ \\
\hline Progressive disease & 2 & 2 & 3 & 4 & 2 & 3 & 3 & $19(61)$ \\
\hline Unknown & 0 & 0 & 0 & 0 & 0 & 1 & 0 & $1(3)$ \\
\hline Overall response rate $(\mathrm{CR}+\mathrm{PR})$ & 0 & 0 & 0 & 0 & 0 & 1 & 0 & $1(3)$ \\
\hline $\begin{array}{c}\text { Disease control rate } \\
(\mathrm{CR}+\mathrm{PR}+\mathrm{SD})\end{array}$ & 1 & 1 & 0 & 1 & 1 & 2 & 5 & $11(36)$ \\
\hline
\end{tabular}

Blood PK profiles for AUY922 on Day 1 of Cycle 2 were similar to those on Day 1 of Cycle 1. The geometric mean of accumulation ratios for $C_{\max }$ (Day 1 of Cycle 1 to Day 1 of Cycle 2) ranged from 1.01 to 1.28 . The ratios for $\mathrm{AUC}_{\text {last }}$ (Day 1 of Cycle 1 to Day 1 of Cycle 2) ranged between 0.992 and 1.60. Hence, there was no significant drug accumulation with once-weekly IV doses of AUY922.

\section{Efficacy}

One patient (rectal carcinoid tumor with lung metastatic lesions) achieved a confirmed partial response (PR) for a duration of $>7$ months (Table 5; Fig. 3). Ten patients (32\%) achieved a best overall response of stable disease (SD) lasting $\geq 8$ weeks, including five out of the eight patients $(63 \%)$ in the $70-\mathrm{mg} / \mathrm{m}^{2}$ cohort; no patients achieved a complete response. The disease control rate (DCR; PR $+\mathrm{SD}$ ) across all dose levels was $36 \%$ (Table 5).

\section{Discussion}

There are a number of HSP90 inhibitors under clinical development, both as single agents and in combination with other agents $[19,20]$. Hepatotoxicity has been reported in both the early and late stages of development of geldanamycin-based HSP90 inhibitors [21, 22]. In this study in Japanese patients with advanced solid tumors, single-agent AUY922 demonstrated an acceptable safety profile at dose levels of $8-70 \mathrm{mg} / \mathrm{m}^{2}$ with potential clinical activity (DCR $36 \%)$. The MTD was not established, and although the BLRM would have permitted further dose escalation, a decision was made not to escalate the dose any further than the well-tolerated dose of $70 \mathrm{mg} / \mathrm{m}^{2}$ based on the potential risk of visual toxicity, the symptoms of which were similar to those reported in the preceding global phase I study (CAUY922A2101), and the RP2D was thus declared as $70 \mathrm{mg} / \mathrm{m}^{2}$ once-weekly.

Hepatotoxicity was not reported as a frequent AE suspected to be related to study drug, or as a DLT; the most common AEs suspected to be related to this study drug included Grade 1 or 2 diarrhea (65\%), night blindness (42\%) and nausea (23\%). Only Grade 1 or 2 visual AEs (most commonly night blindness and photopsia) were reported at the $22-70 \mathrm{mg} / \mathrm{m}^{2}$ dose levels. Similar safety findings were observed in the preceding global Phase I CAUY922A2101 study [14]. Visual disturbances have been reported with other geldanamycin and non-geldanamycin 
Fig. 3 Computed tomography scans of lung metastases in a patient with a confirmed PR following treatment with AUY922 $54 \mathrm{mg} / \mathrm{m}^{2}$ (63 years old, male, primary rectal carcinoid tumor)
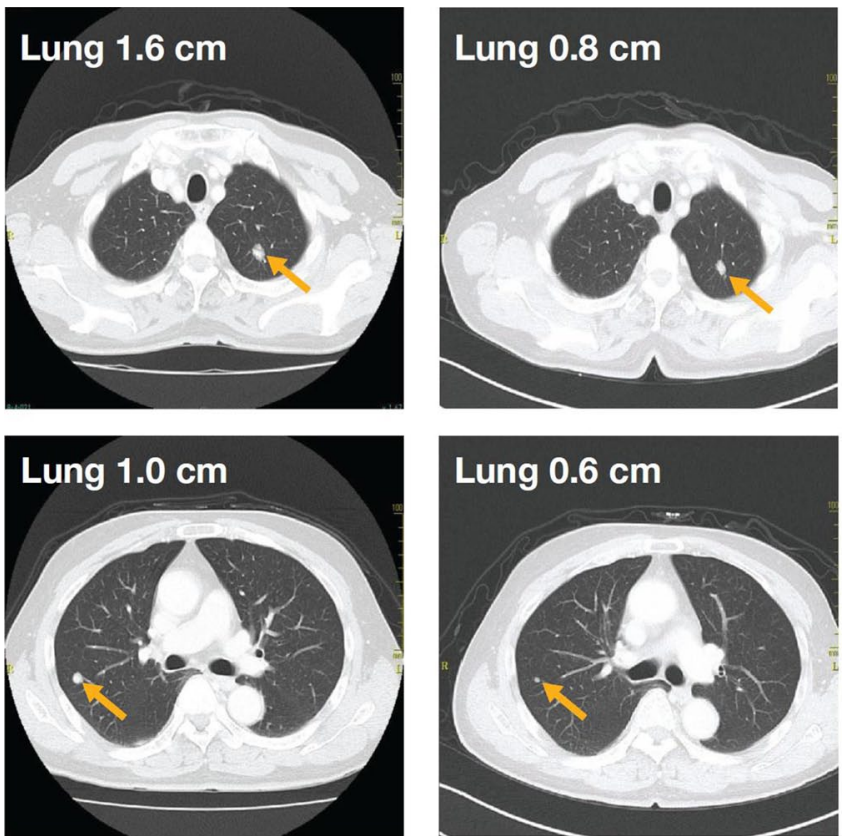

Baseline (24 May 2010)

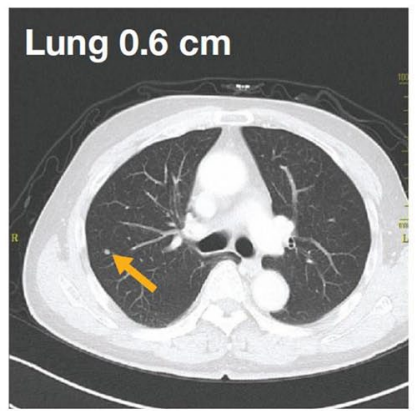

Cycle 7 (18 Nov 2010)
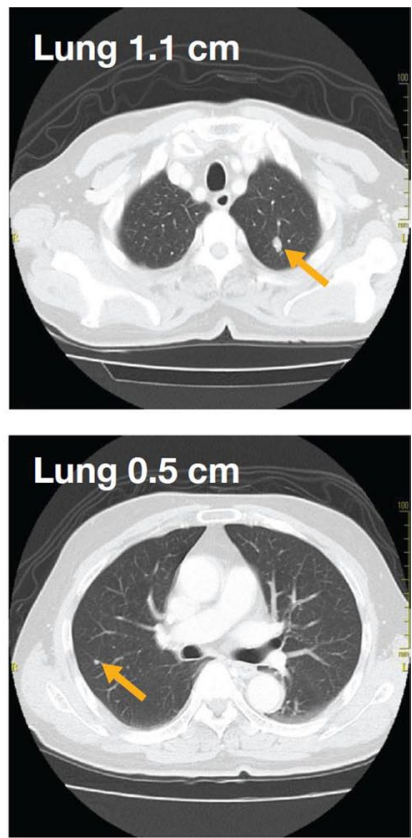

Cycle 8 (12 Dec 2010) PR confirmed
HSP90 inhibitors [23-25]. These visual AEs are regarded as class adverse effects, which are possibly related to tissue distribution of water-soluble agents facilitating a high retina:plasma concentration ratio, as well as the retinal elimination profile [26]. The safety profile of AUY922 was similar to that reported in the preceding CAUY922A2101 study [14], and ongoing Phase II studies $[15,16] . C_{\max }$ for AUY922 in blood increased generally in a dose-proportional manner over the entire dose range. Blood PK parameters of AUY922 in Japanese patients were also comparable to those observed in non-Japanese patients in the CAUY922A2101 study [14]. AUC for AUY922 in blood increased with dose at lower doses, but was saturated at higher doses. This less than dose-proportional increase in blood AUY922 is likely caused by a concentration-dependent and saturable blood cell partition of AUY922. There was no significant drug accumulation following onceweekly intravenous infusion of AUY922.

In summary, AUY922 has shown an acceptable safety profile and demonstrated promising clinical activity in Japanese patients, with one patient achieving a confirmed prolonged PR, and several patients achieving long duration SD at higher dose levels.

Acknowledgments The authors would like to thank the participating patients, their families, all study investigators and research coordinators. Medical editorial assistance was provided by Matthew Naylor, $\mathrm{PhD}$, and was funded by Novartis Pharmaceuticals.

Conflict of interest Toshihiko Doi has received honoraria and research funding from Novartis. Takayuki Yoshino has received honoraria from Takeda, Chugai and Merck Serono, and research funding from Yakult, Taiho, Daiichi-Sankyo, and Lily. Kentaro Yamazaki has received promotional material fees from Takeda and Chugai, and research funding from Taiho and Merck Serono. Narikazu Boku has received honoraria from Taiho, Daiichi-Sankyo, Ono, Yakult, Shionogi, and Takeda, and research funding from Taiho. Matthew Robson and Mikhail Akimov are employees of Novartis, with stock ownership. Other authors have no disclosures to make. This study was designed under the responsibility of Novartis Pharmaceutical Corporation, in conjunction with the steering committee. The study was funded by Novartis Pharmaceuticals Corporation, who collected and analyzed the data and contributed to the interpretation of the study. All authors had full access to all the data in the study, and had final responsibility for the decision to submit for publication.

Open Access This article is distributed under the terms of the Creative Commons Attribution License which permits any use, distribution, and reproduction in any medium, provided the original author(s) and the source are credited.

\section{References}

1. Banerji U (2009) Heat shock protein 90 as a drug target: some like it hot. Clin Cancer Res 15:9-14

2. Mahalingam D, Swords R, Carew JS, Nawrocki ST, Bhalla K, Giles FJ (2009) Targeting HSP90 for cancer therapy. Br J Cancer 100:1523-1529

3. Chiosis G, Neckers L (2006) Tumor selectivity of Hsp90 inhibitors: the explanation remains elusive. ACS Chem Biol 1:279-284

4. Neckers L, Workman P (2012) Hsp90 molecular chaperone inhibitors: are we there yet? Clin Cancer Res 18:64-76

5. Pearl LH, Prodromou C, Workman P (2008) The Hsp90 molecular chaperone: an open and shut case for treatment. Biochem J 410:439-453 
6. Hahn JS (2009) The Hsp90 chaperone machinery: from structure to drug development. BMB Rep 42:623-630

7. Hao H, Naomoto Y, Bao X, Watanabe N, Sakurama K, Noma K, Motoki T, Tomono Y, Fukazawa T, Shirakawa Y, Yamatsuji T, Matsuoka J, Takaoka M (2010) HSP90 and its inhibitors. Oncol Rep 23:1483-1492

8. Trepel J, Mollapour M, Giaccone G, Neckers L (2010) Targeting the dynamic HSP90 complex in cancer. Nat Rev Cancer 10:537-549

9. Brough PA, Aherne W, Barril X, Borgognoni J, Boxall K, Cansfield JE, Cheung KM, Collins I, Davies NG, Drysdale MJ, Dymock B, Eccles SA, Finch H, Fink A, Hayes A, Howes R, Hubbard RE, James K, Jordan AM, Lockie A, Martins V, Massey A, Matthews TP, McDonald E, Northfield CJ, Pearl LH, Prodromou C, Ray S, Raynaud FI, Roughley SD, Sharp SY, Surgenor A, Walmsley DL, Webb P, Wood M, Workman P, Wright L (2008) 4,5-diarylisoxazole Hsp90 chaperone inhibitors: potential therapeutic agents for the treatment of cancer. J Med Chem 51:196-218

10. Eccles SA, Massey A, Raynaud FI, Sharp SY, Box G, Valenti M, Patterson L, de Haven BA, Gowan S, Boxall F, Aherne W, Rowlands M, Hayes A, Martins V, Urban F, Boxall K, Prodromou C, Pearl L, James K, Matthews TP, Cheung KM, Kalusa A, Jones K, McDonald E, Barril X, Brough PA, Cansfield JE, Dymock B, Drysdale MJ, Finch H, Howes R, Hubbard RE, Surgenor A, Webb P, Wood M, Wright L, Workman P (2008) NVP-AUY922: a novel heat shock protein 90 inhibitor active against xenograft tumor growth, angiogenesis, and metastasis. Cancer Res 68:2850-2860

11. Jensen MR, Schoepfer J, Radimerski T, Massey A, Guy CT, Brueggen J, Quadt C, Buckler A, Cozens R, Drysdale MJ, Garcia-Echeverria C, Chene P (2008) NVP-AUY922: a small molecule HSP90 inhibitor with potent antitumor activity in preclinical breast cancer models. Breast Cancer Res 10:R33

12. Jensen M, Ide S, Brueggen J, Schoepfer J, Wang X, Quadt C, Garcia-Echeverria C (2009) Pharmacokinetic/pharmacodynamic relationship of the HSP90 inhibitor NVP-AUY922 in human xenografts and patients in a clinical Phase I trial. Proc Am Assoc Cancer Res, 2009: 5649 [abstract]

13. Gaspar N, Sharp SY, Eccles SA, Gowan S, Popov S, Jones C, Pearson A, Vassal G, Workman P (2010) Mechanistic evaluation of the novel HSP90 inhibitor NVP-AUY922 in adult and pediatric glioblastoma. Mol Cancer Ther 9:1219-1233

14. Sessa C, Shapiro GI, Bhalla KN, Britten C, Jacks KS, Mita MM, Papadimitrakopoulou V, Pluard T, Samuel TA, Akimov M, Quadt C, Fernandez-Ibarra C, Lu H, Bailey S, Chica S, Banerji U (2013) First-in-human phase I dose-escalation study of the HSP90 inhibitor AUY922 in patients with advanced solid tumors. Clin Cancer Res 19:3671-3680

15. Garon EB, Moran T, Barlesi F, Gandhi L, Sequist LV, Kim S, Groen HJM, Besse B, Smit EF, Kim D, Akimov M, Avsar E, Bailey S, Felip E (2012) Phase II study of the HSP90 inhibitor AUY922 in patients with previously treated, advanced non-small cell lung cancer (NSCLC). J Clin Oncol 30(Suppl):7543
16. Kong A, Rea D, Ahmed S, Beck JT, Lopez R, Biganzoli L, Armstrong A, Aglietta M, Alba E, Campone M, Akimov M, Matano A, Lefebvre C, Lee S (2012) Phase IB/II study of the HSP90 inhibitor AUY922 in combination with trastuzumab, in patients with HER2 + advanced breast cancer. J Clin Oncol 30(Suppl):530

17. Neuenschwander B, Branson M, Gsponer T (2008) Critical aspects of the Bayesian approach to phase I cancer trials. Stat Med 27:2420-2439

18. Babb J, Rogatko A, Zacks S (1998) Cancer phase I clinical trials: efficient dose escalation with overdose control. Stat Med 17:1103-1120

19. Gao Z, Garcia-Echeverria C, Jensen MR (2010) Hsp90 inhibitors: clinical development and future opportunities in oncology therapy. Curr Opin Drug Discov Devel 13:193-202

20. Jhaveri K, Taldone T, Modi S, Chiosis G (2012) Advances in the clinical development of heat shock protein 90 (Hsp90) inhibitors in cancers. Biochim Biophys Acta 1823:742-755

21. Demetri GD, Le Cesne A, Von Mehren M, Chmielowski B, Bauer S, Chow WA, Rodenas E, McKee K, Grayzel DS, Kang Y (2010) Final results from a phase III study of IPI-504 (retaspimycin hydrochloride) versus placebo in patients (pts) with gastrointestinal stromal tumors (GIST) following failure of kinase inhibitor therapies. In: ASCO Gastrointestinal Cancers Symposium 2010;64 [abstract]

22. Grem JL, Morrison G, Guo XD, Agnew E, Takimoto $\mathrm{CH}$, Thomas R, Szabo E, Grochow L, Grollman F, Hamilton JM, Neckers L, Wilson RH (2005) Phase I and pharmacologic study of 17-(allylamino)-17-demethoxygeldanamycin in adult patients with solid tumors. J Clin Oncol 23:1885-1893

23. Pacey S, Wilson RH, Walton M, Eatock MM, Hardcastle A, Zetterlund A, Arkenau HT, Moreno-Farre J, Banerji U, Roels B, Peachey H, Aherne W, de Bono JS, Raynaud F, Workman P, Judson I (2011) A phase I study of the heat shock protein 90 inhibitor alvespimycin (17-DMAG) given intravenously to patients with advanced solid tumors. Clin Cancer Res 17:1561-1570

24. Shapiro G, Kwak EL, Dezube BJ, Lawrence DP, Cleary JM, Lewis S, Squires M, Lock V, Lyons JF, Yule M (2010) Phase I pharmacokinetic and pharmacodynamic study of the heat shock protein 90 inhibitor AT13387 in patients with refractory solid tumors. J Clin Oncol 28(Suppl 15s):3069

25. Rajan A, Kelly RJ, Trepel JB, Kim YS, Alarcon SV, Kummar S, Gutierrez M, Crandon S, Zein WM, Jain L, Mannargudi B, Figg WD, Houk BE, Shnaidman M, Brega N, Giaccone G (2011) A Phase I Study of PF-04929113 (SNX-5422), an Orally Bioavailable Heat Shock Protein 90 Inhibitor, in Patients with Refractory Solid Tumor Malignancies and Lymphomas. Clin Cancer Res 17:6831-6839

26. Zhou D (2011) A critical role for the tissue distribution profile in heat shock protein (Hsp) 90 inhibitor-induced ocular toxicity in rats. Mol Cancer Ther 10(Suppl 1):C212 